\title{
Aspectos sobre el Impuesto a la Renta (Corte Suprema)
}

\author{
Comentario de Arturo Selman Nabum
}

Santiago, catorce de agosto de dos mil trece.

VISTOS:

En estos autos del Tribunal Tributario y Aduanero de Tarapacá-Ruc 11-9-00001942-Rit GR-02-00054-2011- Se dictó sentencia de primera instancia que corre a fs. 462, por la que se acogió el reclamo de la sociedad "Servicios Asociados A.M. Limitada", dejándose sin efecto la resolución exenta $\mathrm{N}^{\circ} 1191$ de 20 de junio de 2011, ordenándosele al Servicio de Impuestos Internos que acceda a la solicitud de la reclamante de imputar pagos provisionales de utilidades absorbidas a su FUT, por $\$ 187.967 .646$, debidamente reajustados a la fecha de su entrega, obteniendo así la devolución del Impuesto de Primera Categoría, oportunamente pagado.

En contra de este fallo el servicio aludido, a fs. 556, dedujo recurso de apelación y la Corte de Apelaciones de Iquique, por resolución corriente a fs. 576, lo confirmó, sin mayores consideraciones.

Respecto de esta decisión la parte reclamada -Servicio de Impuestos Internos-a fs. 580, dedujo recurso de casación en el fondo denunciando como errores de derecho, en la parte que se refiere al tratamiento tributario de la venta de acciones, la infracción del artículo $17 \mathrm{~N}^{\circ} 8$ incisos tercero y cuarto, en relación al artículo $31 \mathrm{~N}^{\circ} 3$ de la Ley sobre Impuesto a la renta y, en relación además, a las reglas de interpretación de la ley contenidas en los artículos 19, 20, 21, 22, 23 y 24 del Código Civil. En un segundo acápite se demanda la vulneración del inciso catorce del artículo 132 del Código Tributario, en lo que se refiere a la infracción de las reglas de la sana crítica, todo en relación a lo dispuesto en los artículos $17 \mathrm{~N}^{\circ} 8$ incisos tercero y cuarto de la Ley de la Renta y los artículos 8, 19 N 3 y 76 de la Constitución Política de la República.

Concedido el expresado recurso, por resolución de fs. 597, se ordenó traer los autos en relación.

\section{CONSIDERANDO:}

Primero: Que en el recurso se explica que la sociedad Servicios Asociados A.M. Limitada solicitó administrativamente a la Dirección Regional de Iquique del SII, la devolución del Pago Provisional de Impuesto de Primera Categoría de Utilidades 
Absorbidas (PPUA), correspondiente al año tributario 2009, ascendente a la suma de \$187.967.646. Lo anterior se justificó en atención a la pérdida que permite la absorción de utilidades tributables en una operación de venta de 5.080 acciones de la Sociedad Atacama Bio Natural Products S.A., que la reclamante efectuó a la sociedad Inversiones El Pozo de Pica S.A.C., solicitud que fue denegada por resolución exenta $\mathrm{N}^{\circ} 1.191$, porque se determinó que la venta de las referidas acciones correspondía a una operación afecta al régimen de Impuesto de Primera Categoría en carácter de único, contemplado en el artículo $17 \mathrm{~N}^{\circ} 8$ inciso tercero de la Ley de la Renta, por lo que al no ajustarse dicha venta a una que pudiera enmarcarse dentro del régimen general de tributación, la pérdida originada debía ingresar al Fondo de Utilidades No Tributables, siendo improcedente su imputación al Fondo de Utilidades Tributables (FUT) en los términos pretendidos por la contribuyente. Como se señaló la reclamación fue acogida por la sentencia de primera instancia y confirmada por la Corte de Apelaciones de Iquique;

SEGUNDO: Que se señala en el mismo libelo, que la sentencia recurrida dejó establecido, que para que sea procedente que la pérdida obtenida en una operación de venta de acciones se encuentre afecta al régimen de tributación de Impuesto Único de Primera Categoría se debían de cumplir una serie de requisitos: en primer término, que entre la fecha de adquisición y la de enajenación de las acciones haya transcurrido más de un año y ha quedado asentado como un hecho que la adquisición de las acciones de la reclamante a la sociedad Atacama Bio Natural Products S.A. (Atacama más adelante) se efectuó a partir del año 2005 siendo que su venta se produjo el 12 de diciembre de 2008; que además, no se demostró la existencia de la habitualidad por la inexistencia de medios probatorios que la acreditaran. Se dejó establecido en la sentencia que no existía relación o interés en los términos del No 8 del artículo 17 de la Ley de la Renta, porque no se trataba de enajenaciones que hagan los socios de sociedades de personas o accionistas de sociedades anónimas abiertas dueños del $10 \%$ o más de las acciones, con la empresa o sociedad respectiva, puesto que la reclamante y enajenante de las acciones, no era accionista de la sociedad adquirente al momento en que se verificó la operación, pero a continuación el fallo hace presente que si bien no se incurre en la hipótesis de relación antes descrita, en el caso existiría “interés" en los términos que contempla dicha norma, entendiendo por tanto que como se cumplía con este requisito, se debía circunscribir la operación de venta de acciones de la sociedad Atacama al régimen general de tributación y no al impuesto de primera categoría en carácter de único, correspondiendo en consecuencia imputar la pérdida obtenida al FUT de la empresa enajenante, lo que la habilitaría para solicitar devolución del impuesto antes aludido que fue pagado y que afectó a las utilidades absorbidas. De este modo, se sostiene por el recurrente que de todas las alegaciones hechas por la reclamante, la única razón por la cual se estimó por el fallo que la operación de venta de acciones era una operación afecta al régimen general de tributación, es que la reclamante había tenido un supuesto “interés” en la adquirente de la misma, Inversiones El Pozo de Pica SAC, lo que es inexistente, por lo que resulta contrario a derecho la determinación adoptada en el fallo recurrido de ordenar la restitución de \$187.967.646 por concepto de PPUA; 
Tercero: Que explicando el recurso la forma como se ha producido la infracción de ley, se refiere en primer término a lo que dispone el artículo $17 \mathrm{~N}^{\circ} 8$ de la Ley de la Renta, en la parte referente al tratamiento tributario de la venta de acciones y luego de copiar el precepto en lo discutido, señala que por regla general y así lo declara el fallo, el mayor valor obtenido en la venta de acciones se encuentra gravado con impuesto de primera categoría en carácter de único, constituyendo su regulación una excepción a la tributación conforme al régimen general, vale decir, impuesto a la renta de primera categoría, más impuesto global complementario o adicional, según sea el caso. En este supuesto, se añade, el referido artículo $17 \mathrm{~N}^{\circ} 8$ contempla una serie de hipótesis en las cuales el régimen de tributación en venta de acciones muta del general al excepcional, todas las que de una u otra forma fueron discutidas en autos sobre la conveniencia que le asistía a la reclamante en que la operación de la venta de acciones de la sociedad Atacama, efectuada durante el año tributario 2009, se hubiese enmarcado al régimen general de tributación de la ley de impuesto a la renta y eso es lo que se discutió, para determinar si entre la fecha de adquisición y venta de las acciones había transcurrido más de un año, o que si la empresa enajenante era o no habitual en la venta de acciones o si la misma se encontraba relacionada o tenía interés en la sociedad adquirente. En el fallo de primera instancia, se dice, de todas las situaciones antes referidas, la única hipótesis que se habría cumplido en el caso, para catalogar a la operación de venta de acciones como afecta al régimen general de tributación de la ley de la renta, era la que decía relación con el supuesto interés que la sociedad vendedora o reclamante, tendría en la adquirente, inversiones El Pozo de Pica SAC. Se agrega que aparte de la falta de claridad en la exposición para justificar algo que no correspondía, el solo hecho de entender que la reclamante tenía un interés en la sociedad adquirente, habiéndose asentado previamente que no mantenía una participación accionaria directa o indirecta en la misma ni que tampoco obtenía de ella otro tipo de provecho debidamente acreditado en juicio, hace que el fallo haya errado en la interpretación del inciso cuarto del $\mathrm{N}^{\circ} 8$ del artículo 17 de la Ley de Impuesto a la Renta, de modo que terminó aplicando la norma a una situación de hecho no prevista por el legislador, obligando al Fisco a entregar \$187.967.646 a un contribuyente que no tiene derecho a percibirlo, ya que el régimen aplicable a la venta no habitual de acciones adquiridas hace más de un año, es el impuesto de Primera Categoría en carácter de único. Se sostiene, que el término interés hay que entenderlo conforme a las reglas de interpretación contenidas en el Código Civil, que manda que las palabras de la ley se entenderán en su sentido natural y obvio, según el uso general de las mismas palabras, por lo que según el léxico el significado que debe dársele al termino aludido apunta a un provecho, utilidad, preferencia o conveniencia y ese interés, en la norma aludida, lo debe tener el enajenante en la sociedad adquirente lo que presupone la existencia de algún tipo de vínculo entre ambas entidades anterior a la venta de acciones, de modo que dicho interés debió tenerlo el vendedor en el adquirente y no éste último en el primero, por lo que propone que en un régimen de tributación excepcional resulta acertado concluir que el alcance que debe dársele a la expresión "o en la que tengan intereses" se circunscribe a una vinculación de carácter patrimonial 
o económica, ello de conformidad a las reglas de interpretación contempladas en los artículo 22 y 23 del Código Civil.

En el caso concreto, se sostiene, para que la reclamante hubiese tenido un interés en la adquirente de las acciones, Inversiones El Pozo de Pica SAC, en los términos que exige la norma del artículo $17 \mathrm{~N}^{\circ} 8$ de la ley de la renta, se tendría que haber acreditado en autos una vinculación de carácter patrimonial o económica preexistente a la realización de la referida operación, circunstancia que no solo no se ha acreditado sino que, según se desprende de los considerandos 26 y 28 del fallo de primera instancia ha sido desvirtuada por haber quedado demostrada la inexistencia de un vínculo, desde un punto de vista orgánico-societario, toda vez, que la sociedad Servicios Asociados AM Ltda., no participaba de forma directa ni indirecta en el dominio de Inversiones El Pozo de Pica SAC al momento de la operación de venta de acciones y la única referencia que existe es que dos socios de la primera habrían sido miembros del directorio de la segunda al momento de la venta de las acciones, cuestión que no resulta suficiente para entender demostrado el aludido "interés" a que se refiere la norma que se denuncia infringida. Se agrega que se trata de personas jurídicas las intervinientes en la compra venta de acciones, por lo que resultan distintas de los socios individualmente considerados y por tanto, dichas personas jurídicas, como sociedades eran la que debían demostrar el interés entre sí y no a la existencia de eventuales administradores comunes, como se dejó establecido en los considerandos 31, 32 y 33 del fallo de primer grado, no modificada por la sentencia recurrida, por lo que se pasó por alto la existencia de las personas jurídicas en la operación y no de las persona naturales que intervienen en ellas, con lo cual se ha aplicado el inciso cuarto del $\mathrm{N}^{\mathrm{o}} 8$ del artículo 17 aludido a una situación de hecho no contemplada en dicha disposición, y no la del inciso tercero lo que ha producido que se haga una devolución de una suma de dinero que no debió ser imputada al FUT de la empresa reclamante;

Cuarto: Que como segundo capítulo de errores de derecho, el recurso denuncia la infracción a lo previsto en el inciso décimo cuarto del artículo 132 del Código Tributario, en relación al artículo 17 No 8 incisos 3 y 4 de la Ley sobre Impuesto a la Renta y en relación a lo dispuesto en los artículos $8,19 \mathrm{~N}^{\circ} 3$ y 76 de la Constitución Política de la República. Por la primera norma se faculta al juez para apreciar las pruebas conforme a las reglas de la sana crítica, expresando la sentencia las razones jurídicas y las simplemente lógicas, científicas, técnicas o de experiencia en virtud de las cuales les asigna valor o las desestima. En el caso concreto, se afirma que el tribunal al analizar la prueba debe exteriorizar a través de una sentencia fundada que pueda ser comprendida a cabalidad por las partes, según la doctrina que expresa en su recurso. Afirma que el fallo censurado entra en abierta contradicción con la norma imperativa contenida en el inciso 14 del artículo 132 del Código tributario, por cuanto omite expresar de forma clara y concreta los fundamentos jurídicos que lo llevaron a arribar a la conclusión de que realmente de autos se demostró un interés en la empresa adquirente al momento de la venta de acciones. Al respecto, se sostiene que el fallo reclamado centra su decisión de entender como acreditado dicho "interés" entre empresas sobre la base de un memo 
interno emitido por un abogado del Servicio de Impuestos Internos, que lo afirma y en que dos socios de la reclamante serían también directores de la adquirente de las acciones Inversiones El Pozo de Pica SAC, sin agregar ninguna consideración adicional que informe de qué manera esos dos instrumentos podrían haber generado la convicción de que se cumplía con la situación de hecho contenida en la norma del artículo $17 \mathrm{~N}^{\circ} 8$, inciso 4 de la ley de la renta, haciendo solo una exposición sin razones sobre dicho tema, siendo exiguo en su análisis, deficiencia que trajo como consecuencia la ausencia de una fundamentación jurídica sólida en la que el tribunal apoye su resolución, lo que se demuestra con leer el considerando 57 de la sentencia de primer grado. Se afirma que el memo del abogado es un documento de una carpeta de revisión para rechazar la solicitud de devolución por pérdidas absorbidas, sin indicar porqué ese documento era una prueba idónea para acreditar el hecho discutido, sin relacionarlo con la controversia real para determinar el régimen tributario aplicable a una operación de venta de acciones;

QuiNTO: Que al explicar el recurso la influencia sustancial, que en lo dispositivo del fallo provoca los errores de derecho denunciados, se sostiene, que de haberse interpretado conforme a la ley las reglas legales aplicables al caso, se habría considerado que la venta de acciones que generan el rechazo a la devolución del servicio, tributa conforme al sistema de impuesto único de primera categoría y no en el régimen general de tributación porque no se había acreditado la existencia de un vínculo entre las sociedad de servicios Asociados A. M. Ltda., e Inversiones El Pozo de Pica SAC y al no expresar el fallo las razones jurídicas en que respalda la existencia de un interés no concurrente para los fines de la norma, debió haberse rechazado el reclamo, revocando la sentencia de primera instancia que lo acogió;

Sexto: Que como se ha indica la cuestión jurídica debatida es determinar si la venta en subasta pública de acciones que efectuó la reclamante, que poseía de la sociedad Atacama, rematadas en $\$ 310.000 .000$, valor muy inferior al costo tributario de las mismas y que generó una pérdida tributaria de \$1.926.666.091, con incidencia en el FUT de la empresa, determina o no una devolución por Pagos Provisionales por Utilidades Absorbidas. Esta situación daría lugar, según la tesis de cada una de las partes, a dos sistemas impositivos, determinantes para considerar la existencia de un tributo, uno conforme al sistema general de impuesto de primera categoría, global complementario o adicional que genera el beneficio de rebajar la pérdida del Fondo de Utilidades Tributables, y la devolución consecuente por pagos provisionales por utilidades absorbidas o, de contrario, que esa misma operación, es de aquella que se grava con el impuesto especial único de la renta que no da lugar a la dicha devolución. Es esto último lo que decidió el servicio, porque para desestimar la pretensión del contribuyente, consideró que la operación de venta de acciones se encuentra afecta al régimen de tributación de Impuesto de primera Categoría en carácter de ÚNICO, ya que no es habitual, toda vez, que entre la adquisición y enajenación de las acciones transcurrió más de un año y no se trata de una operación entre empresas relacionadas en 
los términos del inciso 4 del $\mathrm{N}^{\circ} 8$ del artículo 17 de la ley de la renta, no procediendo por ende, la devolución solicitada por la reclamante ya que no se encuentra sujeta la operación señalada al régimen general de tributación lo que no permite absorber utilidades con pérdidas que provienen de otro régimen tributario que pasa a formar parte del Fondo de Utilidades No tributables y no del Fondo de Utilidades Tributables.

Séptimo: Que la sentencia de primera instancia, en el capítulo IV, fojas 522 vta., repite lo que decidió el juez tributario a fs. 286, en cuanto a los hechos que estimó sustanciales, pertinentes y controvertidos en la presente litis, siendo sólo necesario puntualizar el contenido en la letra e) por el cual se pidió demostrar la efectividad de ser la reclamante socia o accionista de la empresa compradora Sociedad de Inversiones Pozo de Pica S.A.C, en los términos señalados en el artículo 17, $\mathrm{N}^{\circ} 8$, inciso cuarto de la Ley de la Renta y que en tal calidad tiene "interés" en la referida empresa compradora. Ello porque, este fue el requisito que la sentencia dio por concurrente para aceptar el reclamo de la contribuyente obligando al Servicio de Impuestos Internos a disponer una devolución de la suma de $\$ 187.967 .646$ por concepto de pagos provisionales por utilidades absorbidas, de modo que la operación de venta de acciones entra en el régimen general de impuesto de primera categoría, global complementario y adicional. Es por lo tanto el fundamento de la casación del servicio aludido y por ello es que deberá analizarse solo sobre este tópico la existencia de los errores de derecho que se denuncian en dicho arbitrio;

Octavo: Que el artículo 17 de la Ley de Impuesto a la Renta, señala los casos de operaciones que no constituyen renta, para los fines de la indicada ley y entre ellas, según el $\mathrm{N}^{\circ} 8$ del mismo precepto el mayor valor, incluido el reajuste del saldo de precio, obtenido en las siguientes operaciones, sin perjuicio de lo dispuesto en el artículo 18 , siendo la renta que interesa, la que se incluye en la letra a) del indicado número: "Enajenación o cesión de acciones de sociedades anónimas, siempre que entre la fecha de adquisición y enajenación haya transcurrido a lo menos un año;". A su vez, el inciso tercero del aludido precepto, establece, en lo que interesa: "La parte del mayor valor que exceda de la cantidad referida en el inciso anterior se gravará con el impuesto de Primera Categoría en el carácter de impuesto único a la renta, a menos que operen las normas sobre habitualidad a que se refiere el artículo 18". Finalmente, el inciso cuarto del indicado artículo 17 preceptúa. "Tratándose del mayor valor obtenido en las enajenaciones referidas en las letras a), ..(entre otras) que hagan los socios de sociedades de personas o accionistas de sociedades anónimas abiertas dueños del $10 \%$ o más de las acciones, con la empresa o sociedad respectiva o en las que tengan intereses, se aplicará lo dispuesto en el inciso segundo de este número, gravándose en todo caso el mayor valor que exceda del valor de adquisición, reajustado, con los impuestos de Primera Categoría, Global Complementario o Adicional, según corresponda";

En este mismo relato es útil consignar lo que en su parte pertinente indica el artículo 18 de la expresada ley: "En los casos indicados en las letras a) del $\mathrm{N}^{\circ} 8$ del artículo 17 , si tales operaciones representan el resultado de negociaciones o actividades 
realizadas habitualmente por el contribuyente, el mayor valor que se obtenga estará afecto a los impuestos de Primera Categoría y Global Complementario o Adicional, según corresponda”.

"Cuando el Servicio determine que las operaciones a que se refiere el inciso anterior son habituales, considerando el conjunto de circunstancias previas o concurrentes a la enajenación o cesión de que se trate, corresponderá al contribuyente probar lo contrario”.

Noveno: Que para los fines de la aplicación en el presente caso de las situaciones previstas en el inciso tercero o del cuarto del $\mathrm{N}^{\circ} 8$ del artículo 17 de la Ley de Impuesto a la Renta, la sentencia de primera instancia, que no fue modificada por la de segundo grado, discurre en el capítulo que individualiza V.7.b) (Fojas 525) que tratándose de la renta generada a consecuencia del mayor valor obtenido en la enajenación de acciones aparece que:"b.1) Dicho mayor valor, por regla general, queda gravado con el impuesto de Primera Categoría con el carácter de Único. B.2) Que solo por excepción y únicamente cuando la enajenación de acciones tiene el carácter de "habitual" dicho mayor valor o renta afecta al régimen general; esto es, se grava con el Impuesto a la Renta de Primera Categoría más Global Complementario o Adicional según sea el caso. B.3) Prueba de lo anterior es la expresión "a menos que operen las normas sobre habitualidad a que se refiere el artículo 18” utilizada por el aludido inciso III, del $\mathrm{N}^{\circ} 8$, del artículo $17^{\circ}$, artículo $18^{\circ}$ en el cual la Ley precisa los casos en que debe entenderse que existe "habitualidad" y -aún más-, confiere al SII facultades legales para establecerla (artículo $18^{\circ}$ de la ley). B.4) el mismo régimen de tributación (Primera más Global Complementario o Adicional) se aplica cuando proceden las "normas de relación" del inciso IV, del artículo $17^{\circ}, \mathrm{N}^{\circ} 8$. (Ver $\mathrm{N}^{\circ} 7$ del considerando siguiente). B.5) En otras palabras, la "renta" obtenida en la "enajenación ocasional o esporádica" de acciones a "empresas no relacionadas" queda afecta al régimen general de tributación que, en este caso -paradojalmente-, no es el régimen general de la Ley (Primera Categoría más Global Complementario o Adicional) sino el mencionado Impuesto Único”. Y como primera conclusión, luego de un análisis probatorio, la sentencia impugnada declara en el motivo $14^{\circ}$ (fs.535) que dará por establecido que las 5.080 acciones de Atacama Bio Natural Products S.A.C. fueron adquiridas por la reclamante con más de un año de anterioridad al 12 de Diciembre de 2008, fecha del remate de que dan cuenta los documentos de fs. 139 y 140 y que consecuentemente, al menos desde el punto de vista temporal, no existe "habitualidad" en la enajenación de las acciones;

DÉcimo: Que luego la sentencia en análisis se preocupa de determinar si la sociedad reclamante, para la adquisición de las acciones que luego enajenó a un menor valor de lo adquirido, modificó la razón social de manera que le permitiera su giro comercial al de "compra y venta de acciones" y si es válido al efecto una actualización de información en dicho sentido un día antes del remate de las acciones y que luego de verificar la prueba rendida al efecto, entre los motivos 15 a 19, concluye en el fundamento 20 que: "este sentenciador dará por establecido y acreditado que para ampliar el giro ante el SII conforme al documento de fs. 133, la reclamante 'no' modificó el giro social de la 
empresa y que dicha ampliación de giro fue realizada ante el SII solo 'un' día antes del remate respectivo, lo cual se determina sin perjuicio de lo que se analiza más adelante respecto de las facultades de los socios;"

Undécimo: Que más adelante la sentencia aludida se refiere a la efectividad de ser la reclamante socia o accionista de la empresa compradora sociedad de Inversiones El Pozo de Pica S.A.C en los términos del artículo 17, $\mathrm{N}^{\circ} 8$, inciso cuarto de la ley de la renta y que en tal calidad tiene interés en la referida empresa compradora. Para dicho efecto, en lo que se refiere a las normas de relación, se explica en el motivo 23 (foja 536 vta.) lo afirmado por la reclamante al afirmar que su empresa tiene interés en la empresa adquirente de las acciones en cuestión, la que finalmente remató, ya que dos de los componentes del directorio de ésta última, son a su vez, socios de la sociedad enajenante, con lo cual se dan los presupuestos que requiere el referido artículo 17 , con lo cual la contribuyente Servicios Asociados AM Ltda., debiera tributar bajo el régimen general y no con el impuesto único. En el análisis que se hace de la prueba en los motivos 24 a 27 , se concluye en el considerando 28 que se dará por probado y establecido que la reclamante y enajenante de las referidas acciones no era accionista de la sociedad adjudicataria Inversiones El Pozo de Pica S.A.C. a la fecha del remate y que el paquete accionario subastado ascendía al 43,33\% de las acciones de las sociedad emisora Atacama Bio Natural Products S.A.;

Duodécimo: Que la sentencia entra a analizar, luego de estimar la inexistencia de los requisitos temporales de adquisición y venta de las acciones en cuestión y de habitualidad, si de todos modos, se da el supuesto de existir entre la reclamante y la adquirente de las acciones rematadas el interés que establece el inciso cuarto del $\mathrm{N}^{\circ} 8$ del artículo 17 de la ley de la renta, que haría aplicable el régimen general de tributación que pretende la sociedad demandante, en la segunda hipótesis legal de dicha norma, para establecer si la enajenante tiene ese interés en la sociedad adquirente. Al efecto, se hace mención, en el fundamento 30 de la sentencia a una opinión del SII a la expresión "interés" en dos dictámenes que señala y, luego, en los considerandos 31 y 32 los testimonios de varios testigos, en la que formulan apreciaciones en ambos sentidos, para concluir en el motivo 33 lo dicho por un abogado del mismo servicio fiscalizador y decidir en el considerando 34 que en estas condiciones, se dará por establecido y acreditado que la sociedad reclamante tiene "interés" en la sociedad adquirente en los términos del aludido inciso cuarto, con lo cual se da el supuesto del precepto: "gravándose en todo caso, el mayor valor que exceda del valor de adquisición, reajustado, con los impuestos de Primera Categoría, Global Complementario o Adicional, según corresponda" y que, consecuentemente, la pérdida respectiva debe ser imputable al FUT de la empresa;

Decimotercero: Que con todo, la sentencia de primera instancia que se analiza y que se confirmó por la de segundo grado, entró a analizar dos alegaciones de fondo para enervar la resolución reclamada por la contribuyente. En efecto, el Servicio reclamado, 
consideró que no concurría la habitualidad que servía para aplicar al caso el sistema general de impuesto de primera categoría, global complementario y adicional, porque entre la empresa adquirente de las acciones y la vendedora de las mismas, Atacama Bio Natural Products S.A. se había producido la situación de complementación industrial, conforme con lo previsto en el artículo 103 de la Ley $\mathrm{N}^{\circ} 13.305$ y 18 de la Ley $\mathrm{N}^{\circ}$ 16.773, que exime de ciertos tributos, cuando una de las empresas involucradas sea dueña de a lo menos el $10 \%$ del capital de la otra y que una de las empresas tenga por objeto la complementación industrial de la otra o el aprovechamiento de capitales, patentes o asesorías técnicas destinadas a mejorar la eficiencia en los procesos de producción y en este entendido el SII declaró administrativamente que no se considerarán habituales las inversiones en acciones de sociedades de complementación industrial de que trata el artículo 103 de la Ley $\mathrm{N}^{\circ} 13.305$, modificada por la Ley $\mathrm{N}^{\circ} 16.773$. El fallo en los considerandos 35 a 53 luego de analizar la prueba sobre este punto declaró en el último fundamento aludido que se demostraba claramente que la compra de acciones de Atacama que hizo la reclamante no fue con el ánimo de venderla ulteriormente sino para producir una evidente complementación industrial entre ambas, por la vía de proporcionarle soporte financiero y asistencial y poder eventualmente gozar de los flujos que aquella pudiera ulteriormente generar. No obstante lo anterior en los motivos posteriores agrega que sobre ese criterio interpretativo, y aún reconociendo la inexistencia de habitualidad el fallo en los motivos siguientes que primaban en todo caso las normas de relación por sobre las de complementación industrial. Finalmente, esa misma sentencia en los motivos finales no acepta, en el presente caso, que ha operado a favor del contribuyente la norma del artículo 26 del Código Tributario, para suponer que la reclamante se ha acogido de buena fe a una interpretación del Servicio de Impuestos Internos;

Decimocuarto: Que como se habrá advertido, con relación a la cuestión jurídica involucrada, la sentencia impugnada, con respecto de la venta de acciones que la sociedad reclamante efectuó a la adquirente Inversiones El Pozo de Pica S.A.C, estableció que existía el interés a que se refiere el inciso cuarto del $\mathrm{N}^{\circ} 8$ del artículo 17 de la Ley de Impuesto a la Renta que permitía que el mayor valor de adquisición se encontraba gravado bajo el régimen general de impuesto de primera categoría, global complementario y adicional y que en su efecto negativo producía una pérdida tributaria para la enajenante que daba lugar, de acuerdo a dicho régimen, para obtener devolución por concepto de PPUA, imputándose al FUT de la misma empresa. Para ello, el fallo aludido, en el considerando 34 señala que "se dará por establecido y acreditado que la sociedad reclamante tiene interés en la sociedad adquirente antes indicada”. Lo anterior se basa en un Ordinario del propio servicio, que se indica en el fundamento 30, en la que el alcance que debe dársele a la expresión "o en las que tengan intereses" es en un sentido amplio y ocurrirá se dice: "cuando en definitiva existe una vinculación patrimonial o un interés económico entre el cedente y el adquirente, ya sea en forma directa o indirecta; es decir cuando la persona que enajena es socia o accionista bajo las condiciones que indican dichas normas de la sociedad adquirente o cuando la persona 
enajenante se encuentra vinculada patrimonialmente o tiene un interés económico con la sociedad adquirente en los términos ya indicados, a través de otras u otras personas jurídicas". En el mismo motivo se indica otro oficio del mismo servicio que sobre el tema señala: "Finalmente se hace presente que el tratamiento tributario descrito precedentemente será aplicable (Impuesto único de Primera Categoría), siempre y cuando no exista vinculación patrimonial o interés económico entre el cedente y el adquirente, caso en el cual será aplicable lo establecido en el inciso cuarto, del $\mathrm{N}^{\circ} 8$, del artículo 17 de la Ley de la renta; esto es, la tributación general que establece la ley del ramo". Luego en el fundamento 31 se justifica la tésis con la declaración de testigos de la reclamante que afirman el interés aludido, por tratarse, entre las empresas que venden y compran, de los mismos representantes legales, que funcionan en un mismo lugar físico, si bien la contabilidad no es centralizada, pero si las personas que trabajan en ella son las mismas y forman parte de un mismo grupo empresarial y el considerando 33 se refiere a la declaración de un funcionario del SII que luego de afirmar que las sociedades no tiene relación entre sí, existe un interés porque dos personas son socias en ambas empresas y José Luis Arenas es representante legal de ambas empresas;

Decimoquinto: Que no obstante las aseveraciones antes señaladas y la declaración del tribunal de considerar existente el interés que habla el inciso cuarto del referido $\mathrm{N}^{\circ} 8$, es lo cierto, que la cuestión que regula la norma es un tema de carácter tributario y por lo tanto, es de naturaleza especial, por la cual se dispone por el precepto en comento -artículo 17- qué actos jurídicos no constituyen renta, mencionándolos expresamente, por lo que su interpretación debe adaptarse rigurosamente a lo establecido expresamente por la norma y, por ello, no es posible establecer en materia de esta naturaleza una interpretación extensiva o analógica. Por eso es que el $\mathrm{N}^{\circ} 8$ aludido, dispone que no constituye renta el mayor valor, incluido el reajuste del saldo de precio, obtenido en distintas operaciones que señala, entre ellas, se menciona la letra a) que es la enajenación o cesión de acciones de sociedades anónimas, siempre que entre la fecha de adquisición y enajenación haya transcurrido a lo menos un año. En el presente caso, es un hecho de la causa, que entre la adquisición de las acciones de la sociedad Atacama que efectuó la contribuyente Sociedad de Servicios A.M. Ltda., y la venta de dichos títulos a la sociedad El Pozo de Pica transcurrió un plazo mayor al del año, por consiguiente dicha operación queda gravada conforme a la ley de la renta, de la manera que se indica en los incisos terceros y cuarto del expresado $\mathrm{N}^{\circ} 8$, para lo cual, según su habitualidad, se impone en el carácter de único o bajo el régimen general. En esta disyuntiva que enfrentó el contribuyente reclamante, para los fines de obtener devolución de PPUA, necesariamente hay que considerar cuál de estas alternativas es la regla general y por lo tanto, la restante, sería lo excepcional y esta última situación lo constituye la norma del inciso tercero, en cuanto dispone que la parte del mayor valor que exceda la cantidad referida en el inciso anterior se gravará con el impuesto de primera categoría en el carácter de único, a menos que operen las normas sobre habitualidad a que se refiere el artículo 18. Como la sentencia recurrida determinó que en la especie no hubo habitualidad, haría excepción a esta norma, lo indicado en el inciso cuarto de 
$\mathrm{N}^{\circ} 8$ añadido, en cuanto dispone que se gravará con el régimen general de impuesto a la renta -Primera Categoría, Global complementario y Adicional- el mayor valor aludido, tratándose de enajenaciones que hagan los socios de sociedad de personas o accionistas de sociedades anónimas abiertas dueños del $10 \%$ o más de las acciones, con la empresa o sociedad respectiva, primera excepción, la que la sentencia en cuestión claramente la tiene como inconcurrente. Pero si considera como tal dicho fallo, en el presente caso, las enajenaciones de las mismas personas en cuanto éstas tengan interés;

Decimosexto: Que sin embargo, ya se ha señalado que la situación del inciso cuarto, se constituye como una excepción a la manera como se tributa este mayor valor, de impuesto de primera categoría en el carácter de único, que regla el inciso tercero a otro de aplicación general por lo que su interpretación debe ser absolutamente acotada al sentido de la norma, en cuanto a las enajenaciones de acciones, ya que como se advierte, a pesar de lo que se afirma por la sentencia en relación a la existencia de este interés, es lo cierto, que es un hecho de la causa que la vendedora, como persona jurídica no era de ninguna manera accionista de la adquirente, Además no se ha establecido como hecho inamovible que entre ambas empresas existiera un vínculo económico que hiciera suponer que la reclamante, como persona jurídica obtenía algún provecho de carácter económico con las actividades productivas de la empresa compradora Inversiones El Pozo de Pica al momento de la venta de las acciones. Eso es lo que se dice en el motivo 30 cuando al contrario de lo que se sostiene, el SII siempre informó que la vinculación del interés debía ser siempre de tipo patrimonial o económico, entre el cedente y adquirente y en el considerando 34, lo que señala en primer término el funcionario a que se alude es que ambas empresa no cumplen los requisitos para ser consideradas empresas relacionadas, pero añade la existencia de un interés porque existirían socios comunes en ambas empresas y que una misma persona sería el representante legal de ambas, que supone una vinculación de carácter personal que a dichas accionistas y representante legal le otorgaría un grado de interés pero que es absolutamente distinto al interés comercial o patrimonial a que se refiere la norma de excepción del inciso cuarto del $\mathrm{N}^{\circ} 8$ del artículo 17 de la ley de la renta. En este entendido es inconcuso que los factores de coincidir socios comunes en las sociedades involucradas, de operar en un mismo lugar físico y de compartir parte de sus trabajadores y que ambas empresas formarían parte de un mismo grupo económico, que pareciera ser la justificación del interés que aduce el fallo impugnado, no logran conformar la excepción del interés a que se refiere el inciso cuarto aludido, que sería el antecedente que permitiría aceptar la pretensión de la contribuyente para la devolución del PPUA, situaciones de hecho que no configuran la modificación del régimen de impuesto único al general que solicita la reclamante;

Decimoséptimo: Que en esta condiciones aparece de manifiesto que la interpretación extensiva que ha efectuado la sentencia recurrida para suponer concurrente en el caso de autos la situación prevista en el inciso cuarto del $\mathrm{N}^{\circ} 8$ aludido, en desmedro de la indicada en el inciso tercero ha importado una trasgresión a los dos preceptos antes indicado, en un caso por dejar de aplicar la situación que importaba el gravamen de 
primera categoría, en calidad de único, al caso de autos y en segundo lugar por considerar atinente a la indicada situación, con error de derecho, que se producía un aspecto de interés no considerado por la norma, yerros jurídicos que han significado disponer una devolución improcedente de impuesto, lo que influye sustancialmente en lo dispositivo del fallo recurrido, amén que además, no se ha dado el debido cumplimiento a lo que ordena el artículo $31 \mathrm{~N}^{\circ} 3$ de la misma ley de la renta que dispone la deducción de pérdidas de ejercicio imputadas a utilidades no retiradas, caso que no correspondía aplicar en la situación del inciso tercero del $\mathrm{N}^{\circ} 8$ del tan repetido artículo 17 de la ley indicada;

Decimoctavo: Que establecido el error de derecho con respecto del primer grupo de infracciones de leyes denunciadas en el recurso de casación, resulta innecesario analizar la procedencia de las vulneraciones que se han promovido con motivo del segundo grupo de infracciones legales contenidas en el mismo libelo, toda vez, que la pretendida infracción de una regla reguladora de la prueba en relación a normas sustantivas no viene al caso, supuesto que sobre la base de los mismos hechos asentados por los jueces del fondo se ha arribado a la infracción de ley que hace procedente el presente arbitrio.

Por estas consideraciones y visto, además, lo dispuesto en el artículo 145 del Código Tributario, 764,767, 785 y 805 del Código de Procedimiento Civil, se acoge el recurso de casación en el fondo, deducido a fs.580, en representación del Servicio de Impuestos Internos, en contra de la sentencia de veintiséis de julio de dos mil doce, escrita a fs. 576 , la que se invalida, por lo que se dictará acto continuo y sin nueva vista, pero separadamente, la resolución que se estima conforme a derecho.

Regístrese.

Dictada por el Ministro Sr. Juica.

Rol No 6.534-12.

Pronunciado por la Segunda Sala integrada por los Ministros Sres. Milton Juica A., Hugo Dolmestch U., Juan Eduardo Fuentes B., Carlos Cerda F. y el abogado integrante Sr. Jorge Lagos G. No firman el Ministro Sr. Cerda y el abogado integrante Sr. Lagos, no obstante haber estado en la vista de la causa y acuerdo del fallo, por estar ambos ausentes.

\section{COMENTARIO}

El presente comentario abordará el pronunciamiento efectuado por la Excma. Corte Suprema en los autos Rol No 6.534-2012, particularmente en dos aspectos, a saber: (A) El sentido o alcance que la Corte atribuyó a la expresión en las que tengan intereses contemplada en el artículo $17 \mathrm{~N}^{\circ} 8$ inciso $4^{\circ}$ de la Ley sobre Impuesto a la Renta (LIR); y (B) Las consecuencias jurídicas del fallo en análisis, toda vez que al acogerse el recurso de casación en el fondo deducido por el Servicio de Impuestos Internos, la Corte implícitamente reconoció que la pérdida ocasionada en una operación afecta al 
Impuesto de Primera Categoría en carácter de Único, no puede ser utilizada para absorber utilidades pendientes de tributación registradas en el Fondo de Utilidades Tributables (FUT), impidiendo en consecuencia una devolución del Pago Provisional por Utilidades Absorbidas (PPUA).

En lo que respecta al primer punto, la Corte analizó ${ }^{1}$ la expresión en las que tengan intereses contemplada en el artículo $17 \mathrm{~N}^{\circ} 8$ inciso $4^{\circ}$ de la $\mathrm{LIR}^{2}$, de manera restringida, especificando que, al tratarse de una norma de carácter tributario, es de naturaleza especial $^{3}$, por ende su sentido o alcance no puede ir más allá de lo que el propio articulado regula. Es del caso destacar que el alcance que la Corte atribuye a la expresión en análisis, no se aleja de lo señalado por el ente fiscalizador en su jurisprudencia administrativa ${ }^{4}$. A modo ejemplar, el Oficio $\mathrm{N}^{\circ} 2.386$ del 2007 señala en lo pertinente: (...) lo dispuesto por dicha norma debe interpretarse en un sentido amplio con el propósito de poder lograr los fines que se persiguen con el establecimiento de tales disposiciones; entendiéndose que la expresión "o en las que tengan intereses" ocurre cuando en definitiva existe una vinculación patrimonial o un interés económico entre el cedente y el adquirente, ya sea en forma directa o indirecta, es decir, cuando la persona que enajena es socio o accionista bajo las condiciones que indican dicha norma de la sociedad adquirente, o cuando la persona enajenante se encuentra vinculada patrimonialmente o tiene un interés económico con la sociedad adquirente en los términos ya indicados, a través de otra u otras personas jurídicas (destacado agregado).

Si bien el Oficio antes indicado comienza señalando que la norma debe interpretarse en sentido amplio, más adelante especifica que dicho interés se verificará siempre que la vendedora sea socia o accionista de la compradora, o cuando el enajenante tenga interés económico en la sociedad adquirente, mediante otras personas jurídicas ${ }^{5}$. Como puede apreciarse, los argumentos vertidos en el considerando décimo sexto de la sentencia son plenamente coincidentes con lo señalado en el Oficio antes singularizado, razón por la cual la mera existencia de socios comunes entre ambas empresas, o que compartan un representante legal, no significa que se configure el interés al que alude el artículo 17 $\mathrm{N}^{\circ} 8$ inciso $4^{\circ}$ de la LIR, por tratarse de una norma especial cuyo sentido o alcance debe

\footnotetext{
${ }^{1}$ Considerandos decimoquinto y decimosexto de la sentencia.

2 Tratándose del mayor valor obtenido en las enajenaciones referidas en las letras a), b), c), d), b), i), j) y k) que hagan los socios de sociedades de personas o accionistas de sociedades anónimas cerradas, o accionistas de sociedades anónimas abiertas dueños del $10 \%$ o más de las acciones, con la empresa o sociedad respectiva o en las que tengan intereses, se aplicará lo dispuesto en el inciso segundo de este número, gravándose en todo caso, el mayor valor que exceda del valor de adquisición, reajustado, con los impuestos de Primera Categoría, Global Complementario o Adicional, según corresponda (redacción vigente antes de la entrada en vigencia de la Ley $\mathrm{N}^{\circ}$ 20.630).

${ }^{3}$ Conclusión que es consecuente con el principio de especialidad, contemplado el artículo 13 del Código Civil.

${ }^{4}$ Ver Oficios números 65 de 1992; 3.150 de 1996 y 2.386 de 2007.

${ }^{5}$ Es del caso destacar que otros Oficios del Servicio de Impuestos Internos han delimitado aún más la expresión en las que tengan intereses, señalando por ejemplo que el interés no se verifica cuando es la compradora quien tiene participación o interés patrimonial en la vendedora, así como tampoco cuando existe vinculación familiar. Ver Oficios números 2.386 de 2007; 1.818 de 2009 y 3.150 de 1996, respectivamente.
} 
interpretarse de forma restringida. No debe olvidarse que el fin último de la norma en discusión es evitar retiros encubiertos, por lo que en términos prácticos no existirá interés en los términos del artículo $17 \mathrm{~N}^{\circ} 8$ inciso $4^{\circ}$ de la LIR, mientras el vendedor no sea socio o accionista de la sociedad adquirente, y en su mérito retire de forma encubierta utilidades pendientes de tributación final.

En lo referente al segundo tópico en comento, es importante señalar que la interrogante respecto si el Impuesto de Primera Categoría y el Impuesto de Primera Categoría en carácter de Único corresponden o no a un mismo impuesto, no fue una cuestión discutida por las partes en el juicio, ni sometida a conocimiento de los tribunales del fondo, lo que no obsta que el pronunciamiento efectuado por la Excma. Corte Suprema, que en definitiva rechazó el reclamo del contribuyente, traiga aparejada la imposibilidad de aprovechar las pérdidas ocasionadas en la venta de acciones afecta al Impuesto de Primera Categoría en carácter de Único.

En efecto, la expresión en las que tengan intereses, solo cobra importancia en el caso en análisis, si entendemos que el Impuesto de Primera Categoría en carácter de Único es diverso del Impuesto de Primera Categoría, ya que si concebimos ambos impuestos como uno solo el contribuyente podría haber aprovechado la pérdida ocasionada en la venta de acciones, independiente si existió interés en los términos del artículo $17 \mathrm{~N}^{\circ} 8$ inciso $4^{\circ}$ de la LIR.

En la actualidad, la principal diferencia en una venta de acciones afecta al régimen general de tributación y al Impuesto de Primera Categoría en carácter de Único, radica que en el primero, el mayor valor se gravará con el Impuesto de Primera Categoría y con el Impuesto Global Complementario o Adicional, según corresponda, mientras que en el segundo solo se gravará el mayor valor con el Impuesto de Primera Categoría, en carácter de Único. Ahora bien, lo importante es determinar si el Impuesto de Primera Categoría comprendido en el régimen general de tributación difiere en forma alguna con el Impuesto de Primera Categoría en carácter de Único. Bajo la mirada del ente fiscalizador, el Impuesto de Primera Categoría en carácter de Único tendría una naturaleza jurídica diversa al Impuesto de Primera Categoría, cuestión que se desprende de las instrucciones del Servicio de Impuestos Internos, particularmente las referidas a su registro, que establecen diferencias importantes entre ambos impuestos.

Sobre el particular, el artículo 14 letra A) No 3 letra a) de la LIR, establece que en el FUT se anotará la renta líquida imponible o la pérdida tributaria del ejercicio, las rentas exentas del Impuesto de Primera Categoría percibidas o devengadas, las participaciones sociales y los dividendos ambos percibidos, así como todos los demás ingresos, beneficios o utilidades percibidos o devengados, que sin formar parte de la renta líquida del contribuyente estén afectos a los Impuestos Global Complementario o Adicional, cuando se retiren o distribuyan.

Por su parte el artículo 14 letra A) $\mathrm{N}^{\circ} 3$ letra b) de la LIR señala que en el mismo registro, pero de forma separada, se anotarán las cantidades no constitutivas de renta y las rentas exentas de los Impuestos Global Complementario o Adicional, percibidas, y su remanente de ejercicios anteriores. Este último registro toma el nombre de Fondo de Utilidades No Tributables (FUNT). Según lo anterior, es dable sostener que la ley no 
señala el registro en que debe anotarse el mayor o menor valor obtenido en una venta de acciones afecta al Impuesto de Primera Categoría en carácter de Único, cuestión que para algunos es prueba suficiente que no existe diferencia alguna entre ambos impuestos.

Sin perjuicio de lo anterior, el Servicio de Impuestos Internos, mediante la Circular $\mathrm{N}^{\circ} 68$ del año $2010^{6}$, reguló el tratamiento tributario que debe otorgarse al Impuesto de Primera Categoría en carácter de Único, señalando entre otras cosas, que las rentas afectas a dicho régimen de tributación deben registrarse en el FUNT. Es del caso señalar que dicha Circular no se encuentra exenta de críticas, así por ejemplo el Profesor Alejandro Dumay Peña ${ }^{7}$ ha señalado que su regulación excedería la facultad interpretativa del Director contemplada en el artículo 6 letra A) $\mathrm{N}^{\circ} 1$ del Código Tributario, por cuanto la referida Circular no indica la norma que estaría interpretando.

Ahora bien, y dejando de lado la crítica antes singularizada, lo cierto es que la instrucción del Servicio de Impuestos Internos, en orden a registrar en el FUNT el mayor o menor valor obtenido en una operación afecta al Impuesto de Primera Categoría en carácter de Único, es consecuente con la regulación y estructura del FUT. En efecto, en el FUT se registran las utilidades (con o sin crédito) de la empresa que se encuentran pendientes de tributación final, las que una vez retiradas o distribuidas al socio persona natural, tributarán según el Impuesto Global Complementario o Adicional según corresponda.

Bajo el esquema antes indicado, resulta lógico que la ganancia ocasionada en una venta de acciones bajo el régimen del Impuesto de Primera Categoría en carácter de Único deba registrarse en el FUNT, por cuanto el trasfondo de dicho impuesto es gravar la operación únicamente con el Impuesto de Primera Categoría, cuestión que no podría materializarse si se registrase la ganancia en el FUT. Ahora bien, si las ganancias deben ser registradas en el FUNT para evitar la tributación del Impuesto Global Complementario o Adicional, según corresponda, parece consecuente registrar también las pérdidas en el referido registro, aunque ello signifique la imposibilidad de aprovechar las pérdidas que pudiesen generarse en la venta de acciones.

Es importante tener presente que la Excma. Corte Suprema, mediante sentencia de fecha 25 de marzo de $1999^{8}$, conociendo de un recurso de casación en el fondo deducido por el contribuyente Supermercado Multiahorro S.A., dictaminó que el Impuesto de Primera Categoría en carácter de Único no es un impuesto diferente al Impuesto de Primera Categoría, por lo que no se justificaría un tratamiento tributario diverso, postura abiertamente contraria a la adoptada en el fallo en estudio.

${ }^{6}$ Que vino a confirmar el criterio expuesto por el Servicio de Impuestos Internos en diversos Oficios dictados con anterioridad a la referida la Circular.

7 Dumay Peña, Alejandro, "Circular Nº 68 del 2010 Ingresos - Costos - Gastos de tipo común”, en Jaque, Javier (dir.), Reportes Tributarios CET UChile, Año 2010, Centro de Estudios Tributarios, Universidad de Chile, Santiago, 2011, pp. 141-156.

8 Corte Suprema, 25 de marzo de 1999, Revista de Derecho y Jurisprudencia y Gaceta de los Tribunales, Tomo XCVI, 1999, sec. $1^{\text {a }}$, pp. 43-49. 
Ciertamente, el fallo en comento no solo es relevante en cuanto a la delimitación de la expresión en las que tengan intereses contemplada en el artículo $17 \mathrm{~N}^{\circ} 8$ inciso $4^{\circ}$ de la LIR, sino que además plantea un cambio de criterio respecto de la naturaleza jurídica del Impuesto de Primera Categoría en carácter de Único, ya que en el momento que la Corte acogió el recurso de casación en el fondo deducido por el Servicio de Impuestos Internos, impidió al contribuyente aprovechar las pérdidas ocasionadas en la venta de las acciones, estableciendo una diferencia evidente con el Impuesto de Primera Categoría. 